\title{
Non-attendance or non-invitation? A case-control study of failed outpatient appointments
}

\author{
Stephen Frankel, Alexandra Farrow, Robert West
}

\begin{abstract}
Objective-To determine the causes of nonattendance at new outpatient appointments.

Design-Case-control study of non-attenders and attenders.

Setting-Outpatient department of a general hospital.

Subjects - All non-attenders $(n=277)$ for first outpatient appointments in six specialties during a three month period were included. Controls $(n=135)$ were the attenders who followed every second nonattender; thus they attended the same consultant on the same day that the non-attenders were expected.

Interventions-None.

Measurements and main results - Information on the clinical problem, difficulties in attending the hospital, and reasons for non-attendance from the questionnaire were coded and classified. Nonattenders had received shorter notice of their appointment than attenders $(14 \% v 1 \%$ had received three days' notice or less). There were small differences in the seriousness of patients' clinical condition.

Conclusions-Client factors are less important than aspects of the service in explaining nonattendance at outpatient appointments.
\end{abstract}

\section{Introduction}

Outpatient departments are at the critical interface between primary care and hospital practice. Here is perhaps the greatest opportunity to influence the use of resources in the pursuit of efficient health care. Nonattendance at outpatient departments may lead to inefficient use of facilities and result in unnecessary costs and delays in assessing patients. Given the concern expressed by managers, planners, and politicians over the consequences of non-attendance ${ }^{1}$ it is surprising how few studies have been reported on this problem as it is experienced in the NHS. This contrasts with the number of studies reported from the United States. The difference in emphasis may reflect the differing economic consequences of nonattendance in the two countries rather than any difference in the scale of the problem.

Studies have concentrated on the social and medical characteristics of non-attenders. Those of lower social class $^{23}$ and from certain ethnic groups ${ }^{45}$ are less likely to attend, though not all studies have found such associations ${ }^{67}$ The dominant assumption in reports as well as in the perceptions of those concerned with managing outpatient care is that non-attendance is primarily a problem of compliance. Such a view begs the question that this study addresses, for it is also possible that the problem is one of non-invitation by the hospital. Accordingly we attempted to answer the more general question "Why do appointments fail?" to avoid the assumptions underlying the usual question
"Why do patients fail to attend?" We differentiated between those factors, such as the appointments system, that lie within the organisation of the service and those factors, such as patients' readiness to attend, that lie outside the service.

\section{Methods}

A case-control design was used to examine possible differences in personal and clinical characteristics of non-attenders and attenders and to be sensitive to factors of specific relevance to the issue of nonattendance of new outpatients. New patients were defined as those seen for a new problem in a particular clinic. Six specialties were selected by their nonattendance rates, their throughput, and the lengths of their waiting lists; these were general surgery; gynaecology; ear, nose, and throat; trauma and orthopaedics; general medicine; and dermatology. All patients who did not attend their first outpatient appointments in these six specialties during a three month period (September to November 1987) were included in the study. They were compared with a sample of attenders drawn from the patients who attended the same clinic under the same consultant on the same day as the cases. A control was the next attender following every second non-attender.

A questionnaire investigated the nature of the clinical problem, the degree of incapacity associated with the clinical problem, any difficulties associated with attending hospital outpatient appointments and in communicating with hospital records and clerical staff, and for non-attenders the reasons for nonattendance. Both open and closed questions were used; for example, the reason for non-attendance was first asked as an open question and later in the questionnaire 14 possible reasons were listed. The questionnaire, which was six pages long, was completed by the patients.

The clinical condition or provisional diagnosis for referral (given in the patient's own words) was classified according to the International Classification of Diseases code and was ranked on a three point scale (non-urgent or non-serious, moderately urgent or serious, and urgent or serious). Classification and coding was done before comparison of cases and controls and analysis.

\section{Results}

After two postings 286 questionnaires were received from the total of 412 patients. Twelve had not been completed adequately and so were excluded from the analysis. This left a final sample of 162 non-attenders and 112 attenders, giving response rates of $58 \%$ and $84 \%$ respectively.

Social characteristics-Table I shows that nonattenders were significantly younger than attenders
Correspondence to:

BrMed f 1989;298:1343-5 
both in the total sample $\left(\chi^{2}=14 \cdot 17, \mathrm{df}=6, \mathrm{p}<0.05\right)$ and among those who responded to the questionnaire $\left(\chi^{2}=\right.$ $13 \cdot 24, \mathrm{df}=6, \mathrm{p}<0.05)$. Non-attenders were slightly more likely to be male, though this difference was not significant $(43 \%$ of non-attenders $v 38 \%$ of attenders in the total sample; $42 \% v 37 \%$ who responded to the questionnaire). Non-attenders who responded to the questionnaire were more likely to be single $(22 \%$ v $16 \%$ of attenders) and less likely to be retired ( $12 \% v, 25 \%)$.

TABLE I-Age and sex of non-attenders and attenders at first appointment in outpatient clinics

\begin{tabular}{|c|c|c|c|c|}
\hline & \multicolumn{2}{|c|}{$\begin{array}{l}\text { Patients who responded to } \\
\text { questionnaire }\end{array}$} & \multicolumn{2}{|c|}{ All patients } \\
\hline & $\begin{array}{c}\text { No }(\%) \text { of } \\
\text { non-attenders } \\
(n=162)\end{array}$ & $\begin{array}{l}\text { No (\%) of } \\
\text { attenders } \\
(n=112)\end{array}$ & $\begin{array}{c}\text { No }(\%) \text { of } \\
\text { non-attenders } \\
(n=277)\end{array}$ & $\begin{array}{c}\text { No }(\%) \text { of } \\
\text { attenders } \\
(n=135)\end{array}$ \\
\hline \multicolumn{5}{|l|}{ Sex: } \\
\hline Male & $68(42)$ & $41(37)$ & $120(43)$ & $51(38)$ \\
\hline Female & $94(58)$ & $71(63)$ & $157(57)$ & $84(62)$ \\
\hline \multicolumn{5}{|l|}{ Age: } \\
\hline $15-24$ & $32(20)$ & $13(12)$ & $64(23)$ & $22(16)$ \\
\hline $25-34$ & $37(23)$ & $15(13)$ & $62(22)$ & 20 (15) \\
\hline $35-44$ & $27(17)$ & $16(14)$ & 46 (17) & 19 (14) \\
\hline $45-54$ & 20 (12) & $20(18)$ & 39 (14) & $22(17)$ \\
\hline $55-64$ & 18 (11) & $22(20)$ & $21(8)$ & $22(15)$ \\
\hline $65-74$ & $14(9)$ & $17(15)$ & $25(9)$ & 19 (14) \\
\hline$\geqslant 75$ & $14(9)$ & $9(8)$ & $20(7)$ & $11(8)$ \\
\hline
\end{tabular}

Clinical characteristics-The seriousness of the clinical condition was assessed on a scale of urgency or severity that was based on provisional referral diagnosis, by the degree to which the patient's activity was limited, by the level of pain, and by the duration of symptoms. There was no significant difference between non-attenders and attenders according to the scale of urgency or severity scale based on their provisional diagnoses (table II). There were small but non-significant differences between attenders and nonattenders with respect to "cutting down on activities" immediately before the appointment and degree of "interference with normal activities" (16\% of nonattenders and $24 \%$ of attenders reported cutting down "a lot" or "completely"), and there were no significant differences between attenders and non-attenders in the duration of symptoms.

TABLE II-Non-attenders compared with attenders at first appointment in outpatient clinics according to severity and implied urgency of their reported diagnoses

\begin{tabular}{lcc}
\hline & $\begin{array}{c}\text { No (\%) of non- } \\
\text { attenders } \\
(\mathbf{n}=162)\end{array}$ & $\begin{array}{c}\text { No (\%) of } \\
\text { attenders } \\
(\mathbf{n}=112)\end{array}$ \\
\hline Diagnosis classified as: & $95(59)$ & $57(51)$ \\
$\quad$ Non-urgent/non-serious & $52(32)$ & $42(38)$ \\
Moderately urgent/serious & $15(9)$ & $13(12)$ \\
Urgent/serious & & \\
\hline
\end{tabular}

Practical issues of access-Non-attenders were slightly more likely to report difficulty in attending outpatient departments: $30 \%$ reported such difficulties compared with $21 \%$ among attenders, though this difference was not significant. The main reason given was difficulty in getting off work $(13 \%$ and $3 \%$ respectively). Fewer non-attenders expected to travel to outpatient departments by private car $(46 \%$ compared with $57 \%$ among attenders).

Patients' understanding of the purpose of the appointment-Non-attenders were marginally less likely to know the purpose of their appointment $(10 \%$ compared with $4 \%$ among attenders), and more nonattenders reported that they had not been given enough information about the appointment. These findings may be biased in that attenders, even if previously unsure, would have been likely to discover the reason for their appointment when they attended.
Notice given of appointment-Non-attenders were much more likely than attenders to have received very short notice of their appointments (table III). These differences were highly significant $\left(\chi^{2}=25 \cdot 1, \mathrm{df}=3\right.$, $\mathrm{p}<0 \cdot 001)$

TABLE III-Notice given of appointments at outpatient clinics as reported by patients answering questionnaire

\begin{tabular}{lcc}
\hline & $\begin{array}{c}\text { No (\%) of non-attenders } \\
(\mathbf{n}=162)\end{array}$ & $\begin{array}{c}\text { No (\%) of attenders } \\
(\mathbf{n}=112)\end{array}$ \\
\hline No of days' notice & & \\
$0-3$ & $22(14)$ & $1(1)$ \\
$4-7$ & $58(36)$ & $34(30)$ \\
$8-14$ & $33(20)$ & $47(42)$ \\
$\geqslant 15$ & $17(10)$ & $20(18)$ \\
Question not answered & $32(20)$ & $10(9)$ \\
\hline
\end{tabular}

Reason for non-attendance-The most commonly reported reasons for non-attendance were being on holiday (28\%), thinking treatment unnecessary $(12 \%)$, difficulties getting off work (12\%), the hospital altering the appointment $(9 \%)$, and feeling too unwell on the day (9\%).

Habitual non-attendance-Twice as many nonattenders (22\%) admitted previous non-attendance at outpatient appointments than did attenders $(11 \%)$, a significant difference $\left(\chi^{2}=6.53, \mathrm{df}=1, \mathrm{p}<0.05\right)$.

\section{Discussion}

The case-control design is sensitive to relatively small differences between non-attenders and attenders. In addition, the direct questions concerning nonattendance or attendance are to some extent concealed, so reducing the effect of bias that arises from recording reasons for non-attendance after the event. Nevertheless, caution is needed in interpreting the differences between non-attenders (cases) and attenders (controls) in that there may be self-justification and rationalisation among non-attenders. The differential response rates indicate that non-attenders were to some extent non-compliers, although for some there may have been practical reasons for non-attendance and noncompliance, such as migration out of the area.

The usual epidemiological characteristics showed little association with non-attendance at a first outpatient appointment. The differences between the social characteristics of attenders and non-attenders were fairly small; there were few important differences in the clinical characteristics of attenders and nonattenders and in their practical arrangements for access to hospital. Non-attenders were younger, more likely to be employed, marginally less disabled, and suffering from marginally less serious clinical conditions, but the differences were not great.

The most striking finding of this study is the short notice that patients seem to be given of their outpatient appointments. Half of non-attenders reported a week's notice or less, which is clearly inadequate. Longer notice would permit patients to reschedule other commitments. The differences between non-attenders and attenders suggest that very short notice may be an important explanation for non-attendance.

Some patients did not seem to have a clear understanding of the reasons for their referral or did not know that they had been referred at all. Such misunderstandings and ignorance offer a partial explanation for non-attendance, and can be remedied only by improved communication between patients and their referring doctors.

This study suggests that client factors may not be as important in explaining failed appointments as is commonly supposed. Indeed, the residual component of non-attendance that is explicable in terms of client 
factors is in general surprisingly low when the financial ${ }^{8}$ and emotional costs ${ }^{9}$ to the patient of attending for services that are sometimes of questionable value are considered. ${ }^{10}$ Other studies support the suggestion that aspects of the service may offer explanations for non-attendance. A study of abortive ambulance journeys found that half of wasted journeys could be attributed to administrative errors such as not notifying the patient or sending the ambulance when the appointment had been cancelled or when the patient had already been admitted. ${ }^{1}$ A Canadian study reported that an appreciable proportion of nonattendance could be attributed to the poor communication of appointments. ${ }^{12}$

The distinction between those factors relevant to non-attendance that arise within the patient population and those that stem primarily from the organisation of the service is important for management. Though there may be interaction between factors arising from patients and from hospital organisation, their implications for planning improvements are quite different. If non-attendance were primarily a reflection of patients' generalised indifference to the service offered then the problem would not be amenable to any straightforward remedies. The identification of important factors of communication and administration, however, suggests that improvements can be expected to follow from fairly simple adjustments in procedure.

Meticulous organisation may produce remarkably low non-attendance rates. ${ }^{13}$ Intervention trials in Canada and the United States have shown that telephone and postal reminders can greatly reduce non- attendance rates. ${ }^{1114}$ Before attributing the problem of non-attendance in the United Kingdom to "the need for hospital patients to recognise their moral responsibility to turn up on time for appointments in order not to waste valuable NHS resources"' it is important to ensure that administrative arrangements are likely to facilitate attendance.

1 The Under Secretary of State for Health, Mr Patten, quoted in Russell W Four million patients who failed to attend. Letter from Westminster. Br.Med F 1984;288:1928.

2 Jonas S. Appointment-breaking in a general medical clinic. Med Care 1971;9:82-8.

3 Stine $\mathrm{OC}$, Chuaqui $\mathrm{C}$, Jiminez $\mathrm{C}$, et al. Broken appointments at a comprehensive clinic for children. Med Care 1968;6:332-9.

4 Alpert JJ. Broken appointments. Pediatrics 1964;34:127-32.

5 Badgley RF, Furnal MA. Appointment breaking in a pediatric clinic. Yale f Biol Med 1961;34:117-23.

6 Schroeder SA. Lowering broken appointment rates at a medical clinic. Med Care 1973;11:75.

7 Hurtado AV, Greenlick MR, Colombo TJ. Determinants of medical care utilization: failure to keep appointments. Med Care 1973;11:189-98.

8 Cawley ME, Stevens FM. Non-attendance at outpatient clinics at the Regional Hospital, Galway, Ireland. Soc Sci Med 1987;25:1189-96.

9 French K, Porter AMD, Robinson SE, McCallum FM, Howie JGR, Roberts MM. Attendance at a breast screening clinic: a problem of administration or attitudes. Br Med f 1982;285:617-20.

10 Stewart IC, McHardy GJR. Audit in a chest clinic. Health Bull (Edin) $1984: 42: 45-50$.

11 Davies P. Why don't patients turn up. Health and Social Service fournal 1984;94:886-7.

12 Grover S, Gagnon G, Flegel KM, Hoey JR. Improving appointment-keeping by patients new to a hospital medical clinic with telephone or mailed by patients new to a hospital medical clinic
reminders. Can Med Assoc $\mathcal{F}$ 1983;129:1101-3.

13 Leese AM, Wilson JA, Murray JAM. A survey of the non-attendance rate at the ENT clinic of a district general hospital. Clin Otolaryngol 1986;11:37-40

14 Bigby JA, Pappius E, Cook EF, Goldman L. Medical consequences of missed appointments. Arch Intern Med 1984;144:1163-6.

(Accepted 22 March 1989)

\title{
First myocardial infarctions in Asian and white men
}

\author{
L O Hughes, U Raval, E B Raftery
}

Abstract

Objective-To compare the presentation and natural course of first myocardial infarctions in immigrant Asians and the indigenous white population in Britain and the subsequent risk states of the two groups.

Design-Prospective ethnic comparison of consecutive patients with first myocardial infarctions.

Setting-Secondary referrals to a coronary care unit of a district general hospital.

Patients-128 Men (77 white, 54 Asian) presenting consecutively with a first myocardial infarction diagnosed on the basis of clinical, biochemical, and electrocardiographic findings.

End point-Identification of mechanisms accounting for the increased rate of ischaemic heart disease in Asians.

Measurements and main results-Infarct size was assessed by measuring the release of creatine phosphokinase (all patients), radionuclide ventriculography (50), and contrast ventriculography (103). Risk states after infarction were assessed from the degree of ventricular dysfunction as determined by exercise electrocardiography (82 patients) and from the extent of coronary atheroma as determined by coronary arteriography (103). Glucose state was measured in fasting venous blood samples. Overall the relative rate of infarction was 4.9 times higher in Asians (95\% confidence interval 3.4 to 6.9 ) than in the white population. Moreover, the relative rate of infarction was higher in Asians in all 10 year age groups, the greatest difference being in 30-39 year olds. The mean age of the Asian denominator popu- lation was $47 \cdot 1$ years compared with $49 \cdot 5$ years in the white population. Age at infarction was less in Asians ( 50.2 years) than in white patients $(55.5$ years; mean difference 5.5 years ( $95 \%$ confidence interval 2.5 to $7 \cdot 1$ )). In Asians the mean creatine phosphokinase activity was 777 (95\% confidence interval 155 to 1399) U/l higher, radionuclide ejection fraction $8.9 \%(1.0 \%$ to $16.9 \%)$ lower, and left ventricular fractional shortening $4 \cdot 8 \%(1 \cdot 4 \%$ to $8 \cdot 2 \%)$ lower than in white patients. The extent of coronary atheroma was significantly greater in Asians. The mean numbers of plaques in vessels not associated with infarction were 3.66 (median 3.0, range $0-10$ ) in Asians compared with 1.97 (median 2.0, range 0-6) in white patients $(\mathbf{p}<0.001)$, and a higher proportion of Asians had three vessel coronary artery disease $(\mathbf{p}<\mathbf{0 . 0 0 1})$. Asians with diabetes or impaired glucose tolerance did not differ from those with normal blood glucose values.

Conclusions-Atherogenesis arises earlier in Asians, contributing to premature first myocardial infarctions. The increased incidence of diabetes in Asians may not in itself be relevant in the greater propensity to coronary atheroma in Asians.

\section{Introduction}

The morbidity and mortality from ischaemic heart disease have been shown to be significantly higher in immigrant southern Asians living in the United Kingdom than in the indigenous population. ${ }^{1-3}$ Retrospective analysis of hospital records suggests a more than twofold greater incidence of acute infarction, ${ }^{+}$and
Dr E B Raftery, Northwick

Middlesex HAl 3UJ.

BrMed f 1989;298:1345-50 